\title{
Dural Puncture Epidural during Labor: A Perspective
}

\author{
Rani $\mathrm{P}^{1}$, Arun Thilak $\mathrm{T}^{2}$
}

\begin{abstract}
Combined spinal epidural (CSE) and epidural (EPL) are the two commonly used neuraxial techniques for labor analgesia. CSE has faster onset but late recognition of epidural failure. EPL produces late onset of analgesia, and quality may not be reliable. Dural puncture epidural (DPE), a modification of the CSE, is a procedure in which the dura will be perforated using a spinal needle with no administration of intrathecal medication. This technique has a faster onset and improved block quality in terms of the caudal spread of analgesia that can be attributed due to the translocation of medication from epidural space into the dural sac. DPE is found to be more effective for labor analgesia with a low dose of local anesthetics with fewer maternal and fetal side effects than the other techniques.
\end{abstract}

Keywords: Bupivacaine, Dural puncture epidural, Obstetric analgesia, Ropivacaine.

Annals of SBV (2021): 10.5005/jp-journals-10085-9109

\section{INTRODUCTION}

Labor pain is subjective and complex. The pattern of the labor pain is different in multiparous and nulliparous women. However, labor pain is considered the highest on the pain-rating scale when compared with other painful experiences. ${ }^{1}$ Maternal pain and stress can result in maternal hyperventilation and the release of catecholamines and cortisol. Therefore, hyperventilation can result in oxygen dissociation curve shift to the left and catecholamine release results in decreased placental blood flow, both of which result in reduced oxygen transfer to the fetus. Studies have shown that unrelieved labor pain can have an effect on the maternal and fetal outcomes.

Neuraxial analgesia is considered the gold standard mode of labor analgesia. Epidural and CSE are the commonly used neuraxial techniques. Epidural has the advantage of providing continuous analgesia and the ability to extend analgesia to anesthesia for cesarean section. However, it has a slow onset of analgesia, and the blockage quality is also variable. Studies have shown inadequacy in sacral spread, patchy or unilateral sensory blockade, motor impairment, and so on. ${ }^{2,3}$ The CSE technique has the advantages of rapid onset, profound analgesia, high patient satisfaction, and verification of epidural space by the definitive return of cerebrospinal fluid (CSF) via the spinal needle, causing reduction in epidural catheter failures. ${ }^{2}$ However, it has the potential of causing hemodynamic instability, fetal bradycardia, and other side effects of intrathecal given local anesthetics and opioids. ${ }^{4,5}$ The disadvantages of both these techniques can be overcome by dural puncture epidural (DPE) technique through better sacral spread, avoidance of spinal drugs, and early identification of epidural failure.

\section{Evolution of Dural Puncture Epidural Technique}

In 1958, Sykes reported an inadvertent dural puncture and medication injection in a vaginal repair patient that gave rise to meiosis, apnea, and hypotension within 15 minutes. ${ }^{6}$ The symptoms were reported to be a result of increased medication spread in the epidural space which is then translocated into the spinal space. With the unplanned dural puncture with an epidural needle by Leach and Smith, DPE technique came into the limelight. ${ }^{7}$ Bernard and Swenson in their in vitro studies

\footnotetext{
1,2Department of Anaesthesiology, Mahatma Gandhi Medical College and Research Institute, Puducherry, India

Corresponding Author: Rani P, Department of Anaesthesiology, Mahatma Gandhi Medical College and Research Institute, Puducherry, India, Phone: +91 9443116908, e-mail: ranip@mgmcri.ac.in

How to cite this article: Rani P, Thilak TA. Dural Puncture Epidural during Labor: A Perspective. Ann SBV 2021;10(2):39-41.

Source of support: Nil

Conflict of interest: None
}

demonstrated the flux of epidural drugs through spinal meninges, and it was directly proportional to the size of the dural hole. ${ }^{8,9}$ In 1996, Suzuki et al. described the first DPE in clinical practice, ${ }^{10}$ and significant improvements and refinement in the technique have been made by researchers in the obstetric field..$^{11}$ Thus, DPE was developed as a procedure in which the dura are perforated using a spinal needle without administration of intrathecal medication.

\section{Mechanism of Action of DPE Technique}

With the dural puncture, a channel is created that plays a pivotal role in the translocation of medication to the subarachnoid space from the epidural space. This results in the onset of better sacral block with improved block quality with fewer maternal and fetal side effects than the other neuraxial techniques. ${ }^{12}$ According to the physics of flow, when the radius of the dural puncture size decreases, the solution passage per unit time also decreases. A study done by Bernards et al. among monkeys analyzed various sizes of dural puncture on the flux of medications, and it showed that the flux of medication had a correlation with the size of the dural puncture. ${ }^{8}$ Park WY has shown that when epidural catheters are inserted, there was greater spread of medications in the cephalad rather than the caudal directions. ${ }^{13}$ In turn the spread in the sacral nerve roots and fibers was more difficult. The CSE technique, in contrast, give direct access to the nerve roots that results in faster onset of analgesia and improved sacral spread. ${ }^{14} \mathrm{~A}$ study done by Cappiello et al. using a 25-gauge Whitacre needle with $0.25 \%$ plain bupivacaine has shown that there was increased

(c) The Author(s). 2021 Open Access This article is distributed under the terms of the Creative Commons Attribution 4.0 International License (https://creativecommons. org/licenses/by-nc/4.0/), which permits unrestricted use, distribution, and non-commercial reproduction in any medium, provided you give appropriate credit to the original author(s) and the source, provide a link to the Creative Commons license, and indicate if changes were made. The Creative Commons Public Domain Dedication waiver (http://creativecommons.org/publicdomain/zero/1.0/) applies to the data made available in this article, unless otherwise stated. 
caudal spread and the median cranial spread was T10 for the dural puncture epidural. ${ }^{2}$ Increased caudal spread and block symmetry were seen among those who had CSE and DPE in a study done by Chau et al. ${ }^{15}$

\section{Dural Puncture Epidural in Obstetric Population}

In the modern world, standard obstetric care in a country is reflected by the availability and acceptance of analgesia for labor. The main goals of labor analgesia are pain reduction, reduced motor block to allow ambulation, allow the women to participate in birthing, and minimal effect on the fetus. ${ }^{16-20}$ To achieve this goal, proper drug/ concentrations, route, and dosage should be accurately delivered. Studies comparing DPE and other neuraxial techniques for labor analgesia are listed in Table 1.

\section{Factors Influencing Transmeningeal Spread of Drug Relation between Size of Dural Puncture and Efficacy of DPE Technique}

Systemic review by Layera et al. showed that there was not much difference between the different size of dural puncture and efficacy of labor analgesia. However, comparatively larger size puncture resulted in faster onset of action. ${ }^{21}$

\section{Drug and Drug Dosage}

Total drug mass constitutes another factor as increased number of drug molecules inside the epidural space will promote sufficient natural transmeningeal diffusion for dural holes, and randomized controlled trials have shown better spread of bupivacaine than lidocaine and that transmeningeal flux of ropivacaine may be similar to that of bupivacaine than lidocaine. ${ }^{18}$

\section{Drugs Used for DPE in Obstetric Population}

Bupivacaine is the most widely used long-acting amide local anesthetic followed by ropivacaine, which is a levorotatory propyl homologue of bupivacaine. Due to its structural features and physicochemical properties ropivacaine is found to be less toxic to the nervous system. Currently available epidural analgesic regimen recommends adding opioids into local anesthetics to provide superior analgesia by sparing local anesthetics and prolonging the analgesic duration. Intermittent epidural bolus technique of labor pain control is preferred over continuous infusion for maintenance in terms of less local anesthetic consumption and less incidence of side effects.

\section{Side Effects in Dural Puncture Epidural Technique}

Adverse effects such as pruritis and maternal hypotension were found to be less reported among the DPE women. ${ }^{15}$ However, symptoms such as back ache, neck ache, and cesarean section were similar in DPE as in other techniques. ${ }^{17}$ Studies have shown that fetal bradycardia was less commonly seen among those who received DPE. ${ }^{15-17}$ The incidence of postdural puncture headache was also minimal with the DPE technique.

Table 1: Studies comparing dural puncture epidural (DPE) technique with group epidural (EPL), and combined spinal epidural (CSE) for labor analgesia

\begin{tabular}{|c|c|c|c|c|c|c|}
\hline S. no. & Study & Design & Objective & Technique & Medication & Findings \\
\hline 1 & $\begin{array}{l}\text { Cappiello O } \\
\text { et al. }{ }^{2}\end{array}$ & $\begin{array}{l}\text { Randomized } \\
\text { controlled trial } \\
(\mathrm{RCT})\end{array}$ & $\begin{array}{l}\text { Onset, sacral spread, } \\
\text { and overall quality } \\
\text { of labor analgesia }\end{array}$ & $\begin{array}{l}\text { Group DPE and group } \\
\text { EPL }\end{array}$ & $\begin{array}{l}12 \mathrm{~mL}-2.5 \mathrm{mg} / \mathrm{dL} \\
\text { bupivacaine }\end{array}$ & $\begin{array}{l}\text { Group DPE had better onset } \\
\text { of analgesia with consistent } \\
\text { S1 dermatome blockade } \\
\text { (bilateral) throughout the } \\
\text { study }\end{array}$ \\
\hline 2 & $\begin{array}{l}\text { Gupta D } \\
\text { et al. }{ }^{17}\end{array}$ & $\mathrm{RCT}$ & $\begin{array}{l}\text { Efficacy between } \\
\text { continuous lumbar } \\
\text { epidural (CLE) and } \\
\text { DPE }\end{array}$ & $\begin{array}{l}\text { Group DPE and group } \\
\text { CSE }\end{array}$ & $\begin{array}{l}0.125 \% \text { bupivacaine } \\
\text { along with } 10 \mathrm{mcg} / \mathrm{mL} \\
\text { fentanyl }\end{array}$ & $\begin{array}{l}\text { DPE had lower immediate } \\
\text { failure rate and higher } \\
\text { incidence of intraprocedure } \\
\text { paresthesia than CLE }\end{array}$ \\
\hline 3 & $\begin{array}{l}\text { Chau A } \\
\text { et al. }^{18}\end{array}$ & $\mathrm{RCT}$ & $\begin{array}{l}\text { Time taken to } \\
\text { numeric pain } \\
\text { rating scale } \\
\text { to } \leq 1\end{array}$ & EPL, DPE, and CSE & $\begin{array}{l}20 \mathrm{~mL} \text { of } 0.125 \% \\
\text { bupivacaine and } \\
2 \mathrm{mcg} / \mathrm{mL} \text { of fentanyl } \\
\text { in group EPL and DPE } \\
\text { and } 1.7 \mathrm{mg} \text { of } \\
\text { bupivacaine and } \\
17 \text { mcg of fentanyl } \\
\text { in group CSE }\end{array}$ & $\begin{array}{l}\text { Onset of analgesia was } \\
\text { most rapid with CSE and } \\
\text { DPE had better sacral } \\
\text { spread }\end{array}$ \\
\hline 4 & $\begin{array}{l}\text { Wilson SH } \\
\text { et al. }{ }^{19}\end{array}$ & $\mathrm{RCT}$ & $\begin{array}{l}\text { Assess the onset of } \\
\text { labor analgesia }\end{array}$ & $\begin{array}{l}\text { Group LE (lumbar } \\
\text { epidural) and DPE }\end{array}$ & $\begin{array}{l}12 \mathrm{~mL} 0.125 \% \\
\text { bupivacaine and } \\
50 \text { mcg fentanyl }\end{array}$ & $\begin{array}{l}\text { DPE was associated with the } \\
\text { much faster time to visual } \\
\text { analog scale } \leq 10 \mathrm{~mm} \text { in } \\
\text { comparison with the } \\
\text { lumbar epidurals }\end{array}$ \\
\hline 5 & $\begin{array}{l}\text { Yadav P } \\
\text { et al. }{ }^{20}\end{array}$ & $\mathrm{RCT}$ & $\begin{array}{l}\text { Onset and } \\
\text { duration of } \\
\text { analgesia }\end{array}$ & DPE and epidural & $\begin{array}{l}10 \mathrm{~mL} \text { of ropivacaine } \\
(0.2 \%) \text { with fentanyl } \\
(2 \mathrm{mcg} / \mathrm{mL})\end{array}$ & $\begin{array}{l}\text { Faster onset, increased } \\
\text { duration of analgesia and } \\
\text { better quality of analgesia } \\
\text { in DPE than epidural }\end{array}$ \\
\hline
\end{tabular}




\section{Conclusion}

Dural puncture epidural technique for labor analgesia has produced improved and consistent block quality, rapid onset, and fewer maternal and fetal side effects than the other techniques. It also produces minimum motor blockade than in CSE and has an additional advantage of early identification of epidural failure. It can be used as a novel option as it offers a favorable risk-benefit ratio.

\section{References}

1. Isanagpur.org. 2018. Labour analgesia. Available from: https://www. isanagpur.org/labour-analgesia/

2. Cappiello E, O'Rourke N, Segal S, Tsen LC. A randomized trial of dural puncture epidural technique compared with the standard epidural technique for labor analgesia. Anesth Analg 2008;107(5):1646-1651. DOI: 10.1213/ane.0b013e318184ec14.

3. Norris MC, Fogel ST, Conway-Long C. Combined spinal-epidural versus epidural labor analgesia. Anesthesiology 2001;95(4):913-920. DOI: 10.1097/00000542-200110000-00020.

4. Cook TM. Combined spinal-epidural techniques. Anaesthesia 2000;55(1):42-64. DOI: 10.1046/j.1365-2044.2000.01157.x.

5. Van de Velde M, Teunkens A, Hanssens M, Vandermeersch E, Verhaeghe J. Intrathecal sufentanil and fetal heart rate abnormalities: a double-blind, double placebo-controlled trial comparing two forms of combined spinal epidural analgesia with epidural analgesia in labor. AnesthAnalg 2004;98(4):1153-1159. DOI: 10.1213/01. ANE.0000101980.34587.66.

6. Sykes MK. Delayed spinal analgesia: a complication of epidural analgesia. Anaesthesia 1958;13(1):78-83. DOI: 10.1111/j.13652044.1958.tb08028.x.

7. Leach $A$, Smith GB. Subarachnoid spread of epidural local anaesthetic following dural puncture. Anaesthesia 1988;43(8):671-674. DOI: 10.1111/j.1365-2044.1988.tb04155.x.

8. Bernards CM, Kopacz DJ, Michel MZ. Effect of needle puncture on morphine and lidocaine flux through the spinal meninges of the monkey in vitro. Implication sor combined spinal-epidural anesthesia. Anesthesiology 1994;80(4):853-858. DOI: 10.1097/00000542199404000-00019.

9. Swenson JD, Wisniewski M, McJames S, Ashburn MA, Pace NL. The effect of prior dural puncture on cisternal cerebrospinal fluid morphine concentrations in sheep after administration of lumbar epidural morphine. Anesth Analg 1996;83(3):523-525. DOI: 10.1097/00000539-199609000-00014.

10. Suzuki N, Koganemaru M, Onizuka S, Takasaki M. Dural puncture with a 26-gauge spinal needle affects spread of epidural anesthesia. Anesth Analg 1996;82:1040-1120. Available from: https://doi. org/10.1097/00000539-199605000-00028.

11. Toledano RD, Tsen LC. Epidural catheter design: history, innovations, and clinical implications. Anesthesiology 2014;121(1):9-17. DOI: 10.1097/ALN.0000000000000239.

12. Gunaydin B, Erel S. How neuraxial labor analgesia differs by approach: dural puncture epidural as a novel option. J Anesth 2019;33(1):125130. DOI: 10.1007/s00540-018-2564-y.

13. Park WY. Factors influencing distribution of local anesthetics in the epidural space. Reg Anesth Pain Med 1988;13(2):49-57.

14. Collis RE, Davies DW, Aveling W. Randomised comparison of combined spinal-epidural and standard epidural analgesia in labour. Lancet. 1995;345(8962):1413-1416. DOI: 10.1016/S0140-6736(95)92602-X.

15. Chau A, Bibbo C, Huang CC, Elterman K, Cappiello EC, Robinson $\mathrm{JN}$, et al. A prospective, randomized trial of standard epidural, dural puncture epidural and combined spinal epidural labor analgesia techniques on maternal and fetal outcomes. AnesthAnalg 2017;124(2):560-569. DOI: 10.1213/ANE.0000000000001798.

16. Bonica JJ. Obstetric analgesia-anaesthesia. London: WB Saunders; 1975:48-72. DOI: 10.1007/978-3-642-49813-8 5.

17. Gupta DE, Sri Raja kaliindi AR, Soskin VI. Dural puncture epidural analgesia is not superior to continuous labor epidural analgesia. Middle East J Anaesthesiol 2013;22(3):309-316.

18. Chau A, Tsen LC. Dural puncture epidural technique: a novel method for labor analgesia. Curr Anesthesiol Rep 2017;7(1):49-54. DOI: 10.1007/s40140-017-0197-6.

19. Wilson SH, Wolf BJ, Bingham K, Scotland QS, Fox JM, Woltz EM, et al, Labor analgesia onset with dural puncture epidural versus traditional epidural using a 26 -gauge Whitacre needle and $0.125 \%$ bupivacaine bolus: a randomized clinical trial. Anesth Analg 2018; 126(2):545-551. DOI: 10.1213/ANE.0000000000002129.

20. Yadav P, Kumari I, Narang A, Baser N, Bedi V, Dindor BK. Comparison of dural puncture epidural technique versus conventional epidural technique for labor analgesia in primigravida. J Obstet Anaesth Crit Care 2018;8(1):24-28 DOI: 10.4103/joacc.JOACC_32_17.

21. Layera S, Bravo D, Aliste J, Tran DQ. A systematic review of dural puncture epidural analgesia for labor. J Clin Anesth 2019;53:5-10. DOI: 10.4103/joacc.JOACC_32_17. 